\title{
Obligations and Intentions: An Exploratory Study of Indirect Cost Recovery Monies from Research Grants as a Revenue Stream for Funding Research Library Budgets
}

\author{
Devin Savage \\ Illinois Institute of Technology, USA \\ Chad Kahl \\ Illinois State University, USA
}

Many academic libraries continue to face budgetary pressures and financial constraints, necessitating an examination of how they meet stakeholder needs. Consequently, academic libraries have seen greater attention given to assessment and student learning. Practically speaking, this laudable focus on student needs also directly connects to primary revenue streams. At higher education institutions that receive research grants, a certain amount of those funds is explicitly designated through Indirect Cost Recovery (ICR) to go to library expenses. Since there are a limited number of ways that an academic library may receive monies, the fact that one of these revenue streams seems to have been almost completely unexplored in the library research literature is quite surprising.

This came to the attention of the authors in quite different ways. One author, working at a private university library, was working with the library faculty committee that was examining different possibilities for increasing the library's budget. Faculty ruled out research grants as an additional source of revenue as library expenses are expressly written into the overhead (indirect) costs that go to the parent institution for providing facilities and administration. Another author, working at a public research university library which received a specific percentage of the research grant monies, was curious about how other university libraries utilized the funds and whether there were any restrictions attached to their use of these funds. Both authors were struck by the paucity of discussion regarding this topic.

In particular, it is a direct and explicit link between the support that a library provides to research in higher education institutions. As noted by Brinley Franklin, "U.S. Office of Management and Budget (OMB) Circular A-21 (the Circular) sets forth the principles by which educational institutions and their libraries can quantify and seek reimbursement for costs incurred in support of sponsored research." ${ }^{\text {These principles have been }}$ updated (as of December 2014) in the Council on Financial Assistance Reform's implementation of the OMB's Federal Uniform Guidance (2 CFR 200), but they still contain guidelines for reimbursement for library expenses. Would not this be a possible pathway to articulate and demonstrate a deficient level of funding for a core mission of the academic library? If academic libraries were able to tie research grant support explicitly to the increasingly expensive collections, this surely could be a lever to push back against decreasing the library share of university expenditures.

This project seeks to explore what the level of awareness of Indirect Cost Recovery (ICR) as a revenue stream is in academic libraries at Carnegie-designated Highest and Higher Research Activity institutions, whether they have specific policies about either ICR designations or expenditures, and how ICR fits in with their other revenue streams.

In addition to seeking and reviewing both library and information science and higher education research literature, the authors deployed a survey to deans and directors of academic libraries in the United States, specifically those at Carnegie Classification Highest Research Activity institutions and Higher Research Activity institutions. An invitation for follow-up conversations on the topic was included. 


\section{The history and changing role of ICR}

Although ICR engenders almost no debate within the library and information science community, it also had little debate within the higher education community, with a few notable exceptions. One of the few times that a larger national debate occurred was in 1991, after a scandal broke about the use of these monies at Stanford University. Robert Rozenweig, then the chair of the American Association of Universities, wrote in the Chronicle of Higher Education about the history and logic for the system:

“...1947, when the Office of Naval Research, then a primary supporter of university-based research, developed a set of principles for determining reimbursement based on actual costs. Throughout the 1950's, most federal grants paid a fixed percentage for overhead costs, while the rates for contracts were negotiated. When university officials complained...that the rates were too low, the government's response was to raise the percentage gradually...In 1958 the Office of Naval Research principles were revised and issued as OMB circular A-21....Applies to research supported by all federal agencies, was designed to allow for variations in university governance and also to permit reimbursement for indirect costs to approach the true costs of research."

Rozenweig noted the logical way to assess the proper reimbursements was not through a case-by-case negotiation, but by creating a charge based upon an aggregate. He specifically used an example of assessing all of the costs for operating campus libraries, negotiating with the government about what portion of those costs can fairly be assigned to federal research on campus. As a result of this attention, in 1991, the OMB put a $26 \%$ cap on administrative ICRs (but not facilities). Another brief discussion about ICR rose again in the late 1990s, as Congress was investigating the increases in facilities and administrative (F\&A) costs. This initial inquiry resulted in a RAND Corporation Science and Technology and Policy Institute Report in 2000. Arthur Beinenstock added his analysis to the report's findings: "Indirect costs, referred to as facilities and administrative (F\&A) costs, are those that cannot be associated with a specific project. Facilities costs include the operation, maintenance, and depreciation of buildings used for the research, research equipment for which the university has paid, interest on debt associated with buildings placed into service after 1982, and library expenses..."3

He goes on to note that other industrialized countries' governments pay for virtually all costs of research, while the United States relies extensively on research universities who are reimbursed only after paying for the infrastructure and staffing and only after successfully competing for the funds. The RAND report noted that universities had lower F\&A costs than federal laboratories or industrial research laboratories. Universities were providing between 0.7 and 1.5 billion reimbursable F\&A research support and were recovering between 70 and $90 \%$ of those costs. Beinenstock contended "Estimates that in 2000, at Carnegie $\mathrm{R} 1$ and R2 institutions, students were paying an average of $\$ 1,000 /$ year to subsidize unrecovered ICR, or more than $50 \%$ of the average tuition increase since $1980 .{ }^{4}$ However, this view should be complicated with Ehrenberg, Rizzo, and Jakubson's 2003 findings that students did bear an increased cost for supporting research in both tuition and class size/adjunctification, but that the effects were surprisingly small. ${ }^{5}$ Furthermore, Phillips and Olson's study finds that cross-subsidies are integral to higher education finance. Student tuition, auxiliary operations (housing, bookstores, etc.), athletics, and research are all subsidized. State appropriations, endowments, and donors all provide the financial base for all other costs to be subsidized to the maximum possible amount. ${ }^{6}$ Still, F\&A cost recovery has never truly covered the full costs of research, and furthermore, ICR reimbursements have not risen concurrently with inflation, which further destabilizes the research environment at universities and tips research towards corporate interests for funding. ${ }^{7}$ In a time where return on investment is a consistent refrain from stakeholders and administrators, this situation suggests further attention to the true costs of research are necessary, especially as the academic library is explicitly identified as a cost to be supported.

\section{What this means for Academic Libraries}

Today, academic libraries face significant and likely unsustainable financial pressures, which the 2017 ACRL Environmental Scan notes "[a]s the public awareness of college costs and student debt grows, so does pressure to contain costs." ${ }^{8}$ Brinley Franklin, the primary source for literature regarding ICR and academic 
libraries, worked extensively with universities on another tactic. He helped recover costs by negotiating ICR rates with the government, often through raising the rate owed to the university designated for library expenses. He found that on average, "...at research universities, 2 percent of sponsored research funding is eligible for recovery as an overhead cost from federal funding agencies to reimburse the universities for library expenses related to funded research." ${ }^{9}$ This makes up about $1 \%$ of the overall revenue at [ARL] Public Research Universities, but ranged from $0.1 \%$ to $10 \% .{ }^{10}$ He suggested "there is a scarcity of information currently available pertaining to how research university libraries are funded" and worried that “...public university research libraries, like their host institutions, may be starting to resemble private university research libraries in the ways they are funded, particularly drawing upon private gifts, student fees, indirect cost revenues, and auxiliary income." ${ }^{11}$ However, this all merely underlines our original research questions. With such an important and explicit role that library expenses play in research, what kind of monies are academic libraries actually receiving, what are they used for, and how does this fit with libraries' other revenue streams?

\section{The Survey}

In order to gain a better understanding of awareness, importance, and use of ICR, we surveyed library deans and directors at 115 Highest Research Activity (R1) institutions and 107 Higher Research Activity (R2) institutions as classified by the Carnegie Classification of Institutions of Higher Education. ${ }^{12}$ Of the R1 institutions, 81 were public and 34 private, and of the R2 institutions, 76 were public and 31 private.

The survey consisted of four parts (see Appendix I):

1. Campus and library characteristics

2. Primary sources of revenue for library budget

3. ICR-specific

4. Would you be interested or available for a short follow-up conversation?

The survey was approved by Illinois Tech's Institutional Review Board (IRB 2018-075), distributed through Qualtrics, and available for responses in October 2018. Survey invitations were sent to 223 potential respondents, which resulted in 221 successful distributions-two emails bounced back repeatedly despite multiple attempts.

\section{Survey responses overview}

Overall, the survey had 58 responses. Of those, 40 were completed (18.1\% response rate). The distribution across public and private institutions and R1 and R2 classifications was relatively consistent with the exception of Higher Research Activity public institutions that were lower than the other type and classification combinations.

- 23 Highest Research Activity (20\%) and 17 Higher Research Activity (15.9\%)

- 13 private and 27 public

- Private institutions

- 7 Highest Research Activity (20.6\%)

- 6 Higher Research Activity (19.4\%)

- Public institutions

- 16 Highest Research Activity (19.8\%)

- 11 Higher Research Activity (14.5\%)

\section{Campus and Library Characteristics (Appendix 2)}

The range of responses was quite substantial. For campus FTE, the largest survey respondent had 32.4 times as many students as the smallest. The respondent with the largest library budget was 46.74 times larger than 
the smallest reported one. The campus annual total research funding amount for the entire institution showed a similar disparity, with the largest being 46.67 times larger than the smallest.

While the Campus FTE and total library budget had similar averages and medians, the annual total research funding for the entire institution had more outlier responses as demonstrated in the substantial difference between the median and average amounts.

\section{Revenue Sources for Library Budget}

Libraries were asked to note the percent of the library budget that came from five different categories with an additional option for "other." Given the large number of no or zero responses, the data was examined with and without those responses. The table below is for respondents with responses greater than zero.

\begin{tabular}{|l|l|l|l|}
\hline & Average & Median & Range \\
\hline $\begin{array}{l}\text { State Support/ } \\
\text { General Appropriations }\end{array}$ & $30.8 \%$ & $73.5 \%$ & $2-98 \%$ \\
\hline Tuition/General Revenue & $46.1 \%$ & $80.0 \%$ & $2-100 \%$ \\
\hline ICR Monies & $0.97 \%$ & $1.9 \%$ & $.005-15 \%$ \\
\hline Student Fees & $6.6 \%$ & $3 \%$ & $0.3-100 \%$ \\
\hline Specific Endowments & $5.99 \%$ & $5 \%$ & $1-45 \%$ \\
\hline
\end{tabular}

Student fees could be library fees, technology fees, etc. Responses for "Other" included fundraisers, grants, contracts, federal appropriations, and unknown. Some respondents noted that funds appropriated to the library combined different categories of funding.

Particularly interesting were that the ICR monies response average was $0.97 \%$ (of those with responses) compared to $0.95 \%$ that Brinley Franklin noted in 2007, which demonstrates little change in the past decade. ${ }^{13}$ Researchers also noted that ICR monies are less than one-sixth the averages for student fees and specific endowments.

\begin{tabular}{|l|l|l|l|l|l|}
\hline & Yes & No & Range & Yes and No-Average & Yes-Average \\
\hline $\begin{array}{l}\text { State Support/ } \\
\text { General } \\
\text { Appropriations }\end{array}$ & 21 & 20 & $0-98 \%$ & $31.5 \%$ & $61.6 \%$ \\
\hline $\begin{array}{l}\text { Tuition/ } \\
\text { General Revenue }\end{array}$ & 25 & 16 & $0-100 \%$ & $44.9 \%$ & $73.7 \%$ \\
\hline ICR Monies & 12 & 29 & $0-15 \%$ & $1.2 \%$ & $4.1 \%$ \\
\hline Student Fees & 14 & 27 & $0.3-100 \%$ & $7.1 \%$ & $20.7 \%$ \\
\hline $\begin{array}{l}\text { Specific } \\
\text { Endowments }\end{array}$ & 30 & 11 & $1-45 \%$ & $8.2 \%$ & $6.0 \%$ \\
\hline Other & 10 & 31 & $1.7-100 \%$ & $9.3 \%$ & $38.2 \%$ \\
\hline
\end{tabular}


Of those that reported the use of these revenue sources, the most substantial-not surprisingly-were state support/general appropriations and tuition/general revenue. For the roughly half that reported the former, it amounted to more than three-fifths of their budget (61.6\%) and of the roughly three-fifths that reported the latter, it was nearly three-quarters (73.7\%). Of the third of the respondents that reported the use of student fees, it was roughly one-fifth of their budget (20.7\%)-the average was greatly influenced by the two respondents who receive $100 \%$ of the budgets from student fees. The most common revenue source were specific endowments with 30 institutions reporting their part in the library budget. "Other" was the least common response, but of those that responded, it contributed on average to nearly two-fifths of the budget (38.2\%) -this was another response that had a sizable range of responses.

\section{ICR-Specific (Appendix 3)}

Of the twelve libraries that reported receiving ICR monies, this revenue source was $4.1 \%$ of their budget. Of all the reporting institutions that included no or zero responses, the percentage was down to $1.2 \%$ of their budget.

Of the twelve libraries that reported receiving ICR monies, only five noted they received a set percentage: $1.95 \%, 2 \%, 3 \%, 3 \%$, and $10 \%$. Of those five, in terms of campus oversight, only one reported any specifications or stipulations on the use of the ICR monies. Only four noted that the use of the ICR money was tracked and/or reported-primarily for financial and monitoring purposes. Only two had policies regarding carryover of the funds.

In terms of other effects of the rest of the campus on the libraries, in response to the question, "Does rise and fall of total research funding at the institutional level affect ICR monies to library?" nearly half (6) responded "yes." The affirmative responses noted there was not much of an effect given the stability in the small amounts and they were typically utilized for non-essential purposes.

In general, library usage of ICR monies are not well understood internally by the library or externally by campus. Despite the lack of clarity, there have been discussions between the library and campus. Of the ten responses, the following had multiple mentions: lack of unawareness of any conversations, lack of formula or policy, and description of methods of fund distribution or expenditures.

A number of questions were posted but did not receive any responses:

- Does the library itself set any preferred or policy specifications for the spending of these ICR monies?

- Why does the library set preferred or policy specifications for the spending of ICR monies?

- What purpose(s) does the library use the ICR monies for?

- What purpose(s) would the library like to use ICR monies for, but does not feel permitted to do so?

Two respondents volunteered for follow-up conversations. Those conversations had three common themes: a tension between the library's ability to use the funding effectively and campus pressure to spend to prevent large build-up of funds; interest in learning from other libraries' use of ICR funds; and an interest in what strategies have been utilized by others to identify and effectively lobby campus partners to impact this source of funding.

In terms of the tension between the library and campus, both noted there is a reluctance to use the funds because they are seen as a "rainy day" fund to deal with flat or reduced allocations, budget cuts or rescissions, or unexpected costs. On the other hand, any account in a public university that looks like it is sitting unspent makes it more challenging for the parent institution to request additional general revenue funds. Each had examples where sizable portion of ICR funds were converted to general revenue funds to ensure they were spent more readily. 
Moreover, since the fund amounts are typically small and variable, there is reluctance to use them for sizable, recurring costs (e.g., electronic resource subscriptions). Should these funds be unavailable or greatly reduced in one year, the library would have to identify an alternative source of funding. However, library leaders were interested in seeing how other libraries utilized these funds in an innovative manner and if they were able to spend the ICR funds on something that had recurring costs, such as database expenditures. Also, they both noted a desire to use the funds to supplement library and information science faculty activity and research. Other possible uses mentioned included funding open access initiatives, such article processing charges creating partnerships for graduate student research funds, or for focused library facilities-related expenditures. There was a general curiosity on how the university came to the decision to appropriate the amounts, how percentages were chosen, and so forth. Intriguingly, there was a clear desire to know what might be other innovative uses for such funds, as well as identifying pathways to open conversations about this revenue stream across campus.

\section{Possible future directions for the research}

Since the survey was confidential, but not anonymous, the researchers could utilize other information resources (such as IPEDS, institutional websites, and the Council on Governmental Relations) to fill in missing survey responses and/or look for possible correlations. Each institution has other Carnegie classification identifiers that could be utilized for comparative purposes. Promising options include undergraduate program and graduate program profiles that note balance of majors with professional programs and level of overlap with graduate programs (e.g., "Arts \& sciences plus professions, high graduate coexistence," "Research Doctoral: Comprehensive programs, no medical/veterinary school"). Other possibilities include enrollment profiles (e.g., "Four-year, full-time, more selective, lower transfer-in"), size and setting (e.g., "Four-year, medium, primarily nonresidential"), or community engagement designation. Further investigation could utilize other methodologies to focus attention on the ICR-specific questions that did not receive responses. And given the primacy, range, and size of the other revenue sources reported by libraries, research focus could shift to non-ICR options.

In conclusion, Brinley Franklin's observation is that the “...government allows educational institutions to seek reimbursement for library expenses related to funded research...[which] has given American academic institutions an incentive to measure the extent to which their academic libraries support sponsored research." ${ }^{14}$ It offers a necessary reminder to neither neglect important stakeholders, nor to forget an important part of our mission as academic and research libraries. Although the level of ICR monies funding at institutions is generally lower than other revenue streams, given the explicit link between library services and the F\&A portion of this type of funding, it merits further discussion. As costs of electronic resource subscriptions continue to outpace the rate of inflation, it seems striking that there has not been a reconsideration of the support needed from ICR, and we hope that this is the beginning of a renewed conversation on this topic.

-Copyright 2019 Devin Savage and Chad Kahl

Devin Savage

Associate Dean for Assessment and Scholarly Services

Paul V. Galvin Library, Illinois Institute of Technology

Chad Kahl

Associate Dean for Public Services and Technology

Millner Library, Illinois State University

\section{Endnotes}

1. Brinley Franklin, "Academic Research Library Support of Sponsored Research in the United States," Proceedings of the 4th Northumbria International Conference on Performance Measurement in Libraries and Information Sciences (August 2001): 105. 
2. Robert M. Rozenweig, "Debate over Indirect Cost Raises Policy Issues,” The Chronicle of Higher Education, March 6, 1991.

3. Arthur Bienenstock, "A Fair Deal for Federal Research at Universities," Issues in Science and Technology 19, no. 1 (Fall 2002): 33.

4. Bienenstock, "A Fair Deal," 36.

5. Ronald G. Ehrenberg, Ronald J. Rizzo, and George H. Jakubson, Who Bears the Growing Cost of Science at Universities no. w9627 (Cambridge, MA: National Bureau of Economic Research, 2003), http://www.nber.org/papers/w9627.

6. Cynthia R. Phillips and Jeffrey E. Olson, "To What Extent are the Final Cost Objectives of Universities Subsidized?" in Proceedings of ASBBS 20, no. 1, http://asbbs.org/files/ASBBS2013V1/PDF/P/Phillips_Olson(P722-737).pdf.

7. Robert D. Honigman, "The Myths about Indirect Costs," The Chronicle of Higher Education, December 14, 1994; Christopher Newfield and Gerald Barnett, "The Federal Stimulus Should Support Research at Public Universities," Chronicle of Higher Education, 3 January 2010; and Frank A. Anania, "Universities and Sponsored Research: Indirect Cost Recovery and the Law of Diminishing Return," Hepatology 61, no. 6 (June 2015): 1776-1778, https://doi.org/10.1002/hep.27776.

8. ACRL Research Planning and Review Committee, Environmental Scan 2017 (Association of College \& Research Libraries, March 2017), http://www.ala.org/acrl/sites/ala.org.acrl/files/content/publications/whitepapers/EnvironmentalScan2 017.pdf.

9. Brinley Franklin, "The Privatization of Public University Research Libraries," portal: Libraries and the Academy 7, no. 4 (October 2007): 412, https://doi.org/10.1353/pla.2007.0046.

10. Franklin, "The Privatization of Public University Research Libraries," 412.

11. Ibid, 413.

12. The Carnegie Classification of Institutions of Higher Education, accessed July 5, 2018, http://carnegieclassifications.iu.edu/.

13. Franklin, "The Privatization of Public University Research Libraries," 412.

14. Brinley Franklin, “Academic Research Library Support,” 105. 


\section{Appendix 1: The Questions}

1. Demographic questions about institution
a. Public/Private
b. Size/Carnegie research classification (radio button for highest or higher research activity)
c. Campus student FTE
d. Total library budget
e. Annual total research funding amount received for whole institution (if known)

2. Demographic of the person answering the survey
a. Job title

3. Besides Indirect Cost Recovery monies, what are the primary sources of revenue for funding your budget? (check all that apply: state support/appropriations (if applicable), tuition/general revenue, student fees (e.g., library, technology), specific endowments, other [entry box for responses])

a. Ranking or percentage, if known?

4. Are any Indirect Cost Recovery monies designated to go to the library budget?
a. If so, is there a specific set percentage?
b. Are there any specifications or stipulations for the use of those monies?
c. What are those stipulations or specifications?

i. Please copy and paste any other relevant language or text

5. Does the library itself set any preferred or policy specifications for the spending of these monies? Please copy and paste any relevant language or text.
a. Why?
b. What purpose(s) do you use the funds for?
c. What purpose(s) would you like to use Indirect Cost Recovery funds for, but do not feel permitted to?

6. Is the library usage of Indirect Cost Recovery monies to support resource acquisition, support services, or other purposes tracked and/or reported? If so, for what purpose?

a. How are the effects of impact of this support (or lack thereof) understood, valued, and/or articulated by the library?

7. Does the rise and fall of total research funding at the institutional level affect the revenue to the library? If so, what has been the impact that you have observed? 
8. If the library receives Indirect Cost Recovery monies from campus, are there any policies regarding the carryover of funds (e.g., a requirement to spend a certain percentage a year)?

9. Briefly tell us about any experiences, conversations, etc. regarding Indirect Cost Recovery monies on your campus in relationship to the library.

10. Would you be interested or available for a short follow-up conversation? If so, please list your contact information:

\section{Appendix 2}

Completed responses only

\section{Campus FTE}

- $\quad$ average: $22,490.77$

- median: $19,776.5$

- $\quad$ range: 2,500 -nearly 81,000

\section{Total library budget}

- average: $\$ 18,704,882.50$

- median: $\$ 17,220,626$

- range: $\$ 1,192,111-\$ 55,725,125$

Annual total research funding for entire institution, if known

- $\quad$ average: $\$ 330,953,568.30$

- median: $\$ 140,000,000$

- range: $\$ 30,000,000-\$ 1,400,000,000$

- "unknown" or similar responses $=5$

Appendix 3

Completed responses only

Are any Indirect Cost Recovery (ICR) monies designated to go to the library budget

- $\quad$ yes $=12$

- $\mathrm{no}=27$

If your library receives any ICR monies, is there a set percentage?

- $\quad$ yes $=5$

- $2 \%$

- $1.95 \%$

- $3 \%$ (from the top)

- $3 \%$

- $10 \%$

- no $=7$

If your library receives ICR monies, are there any specifications and/or stipulations for the use of those monies? (responses from the five libraries that receive ICR Monies) 
- $\quad$ No: 4

- Yes: 1

What are those specifications and/or stipulations for the use of ICR monies?

- "Must be used to support journal and software subscriptions"

- "To support faculty research"

Is the library usage of ICR monies to support resource acquisition, support service, or other purposes tracked and/or reported?

- Yes: 4

- No: 8

For what reason(s) is/are the library usage of ICR monies tracked and/or reported?

- We are an RCM campus (budget model); therefore, ICR is distributed to the unit that generates the ICR. The Libraries receive ICR that is associated with our own grants, not from collegiate grants. All ICR for collegiate or other institutional research is attributed to the unit that generates the grant.

- Financial reconciliation

- Tracked via normal budget process to see what was expended on subscriptions

- To monitor the expenditure of funds

How are the effects of the library usage of ICR monies understood, valued, and/or articulated by the library?

- NA (see last question)

- It is unclear

- This process in in the first year and so we have not articulated the value yet. However, the ICR monies are the reason we have not had to cut journal subscriptions.

- Not well understood in the past. However, efforts are underway to educate the Libraries' administration to its availability and usage purposes

Does the rise and fall of total research funding at the institutional level affect the ICR monies to the library?

- Yes: 6

- "So far, not much impact, because the amounts are not too variable year by year

- "These funds have been relatively stable, but have decreased once in the last decade when total funding decreased."

- "We use the monies for special projects so it has less of an effect"

- "very little, as we are (perhaps overly) cautious about spending these funds anyway"

- "Less ability to offer travel to professional development activities for faculty"

- "Historically, we hover around the 2 percent range but in some years have received more based on the research dollars."

- No: 6

Are there any policies regarding the carryover of ICR monies (e.g. a requirement to spend a certain percentage each year)?

- Yes: 2

- "The monies are to be spent in the fiscal year received." 
- $\quad$ “...depends on whether the IDC is following a PI or the office of the dean. Monies stay with PI, monies allocated to Deans may be swept if there is carryover. Library only receives IDC as part of our own grants or similar agreements, not as a general portion of research dollars. Cost recovery in grants for "library" is just part of general overhead."

- No: 10

Please briefly tell us about any experiences, conversations, etc. regarding ICR monies on your campus in relationship to the library.

- Before RCM, collegiate ICR did flow to the Libraries, but not based on any formula or policy. Under RCM, attribution of ICR to the Libraries (other than that which we generate) doesn't fit the model.

- Affirmed ICR monies through MOUs

- $\quad$ None that I am aware of.

- IRC monies are one funding source that makes up the general university allocation and are not broken out as a separate source of funds in the libraries budget.

- The way it is set up is very beneficial to the library and there is no heavy handed oversight, so far.

- As I said, this is a new arrangement between the Libraries and the Office of the Provost. It was put in place to remove subscription increase requests from the normal budget request process. We are piloting a lump sum distribution from the Provost's ICR monies that goes directly to journal, database and software subscriptions. The lump sum was calculated using industry figures and historical data. We agreed on a lump sum for 3 years with review after the 3 rd year.

- Within the library, we discuss improving our planned use of the funds. No discussions outside the library of which I am aware.

- I should clarify that the foregoing responses refer only to indirect cost recovery via grants awarded to the libraries and specific allocations of indirect cost recovery funds to library initiatives. There have been no discussions to my knowledge about the use of indirect cost recovery funds to support general library operations.

- It often comes up that there is a library cost recovery (usually people talk about it as somewhere around 4\%) on grants and "why isn't that allocated to us directly" and in a transparent manner. The answer historically has been that it is just part of the general overhead for campus facilities and services, it keeps the lights on, etc. At another institution I did see the specific federal formula/calculation for library cost recovery on grants, but again, it did not appear as a direct fund to the library.

- I'm only interim, but my understanding is that the formula was worked out in the 70s, and ever since then the budget has been a request to the provost based on previous year plus increase in collections costs. 